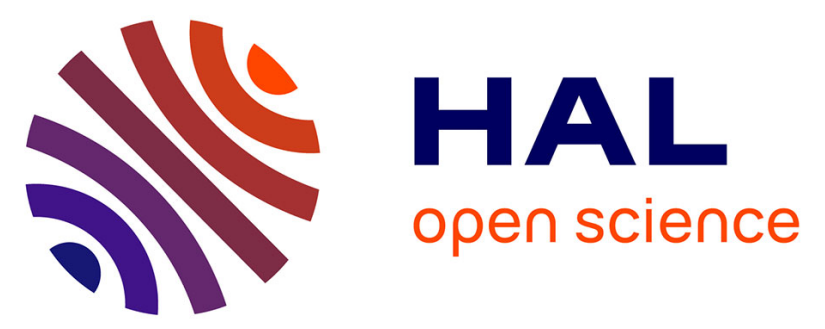

\title{
Moxifloxacin-rifampicin combination for the treatment of non-staphylococcal Gram-positive orthopedic implant-related infections
}

F. Fily, A. Jolivet-Gougeon, E. Polard, T. Gicquel, M. Dupont, M.C. Verdier, C. Arvieux

\section{To cite this version:}

F. Fily, A. Jolivet-Gougeon, E. Polard, T. Gicquel, M. Dupont, et al.. Moxifloxacin-rifampicin combination for the treatment of non-staphylococcal Gram-positive orthopedic implant-related infections. Médecine et Maladies Infectieuses, 2019, 49, pp.540 - 544. 10.1016/j.medmal.2019.06.008 . hal03487660

\section{HAL Id: hal-03487660 \\ https://hal.science/hal-03487660}

Submitted on 21 Dec 2021

HAL is a multi-disciplinary open access archive for the deposit and dissemination of scientific research documents, whether they are published or not. The documents may come from teaching and research institutions in France or abroad, or from public or private research centers.
L'archive ouverte pluridisciplinaire HAL, est destinée au dépôt et à la diffusion de documents scientifiques de niveau recherche, publiés ou non, émanant des établissements d'enseignement et de recherche français ou étrangers, des laboratoires publics ou privés.

\section{다(1) $\$$}

Distributed under a Creative Commons Attribution - NonCommerciall 4.0 International 
Moxifloxacin-rifampicin combination for the treatment of non-staphylococcal Grampositive orthopedic implant-related infections

\section{Association moxifloxacine et rifampicine dans le traitement des infections ostéoarticulaires sur matériel à bactéries à Gram positif hors staphylocoque}

F Fily ${ }^{1,2}$, A Jolivet-Gougeon ${ }^{3,2}$, E Polard ${ }^{4,2}$, T Gicquel ${ }^{5,2}$, M Dupont ${ }^{1}$, MC Verdier ${ }^{4,2}$, C Arvieux ${ }^{6,2}$

${ }^{1}$ Unité des maladies infectieuses, Hôpital Broussais, 1 rue de la Marne, 35400 Saint Malo, France.

${ }^{2}$ Centre de Référence pour les Infections Ostéo-articulaires Complexes du Grand Ouest (CRIOGO), Centre Hospitalier Universitaire Rennes, 2 rue Henri le Guilloux, 35033 Rennes, France.

${ }^{3}$ Laboratoire de microbiologie, Centre Hospitalier Universitaire Rennes, 2 rue Henri le Guilloux, 35033 Rennes, France.

${ }^{4}$ Service de pharmacologie clinique et biologique et centre de pharmacovigilance, Centre Hospitalier Universitaire Rennes, 2 rue Henri le Guilloux, 35033 Rennes, France.

${ }^{5}$ Service de chirurgie orthopédique et traumatologique, Centre Hospitalier Universitaire Rennes, 2 rue Henri le Guilloux, 35033 Rennes, France.

${ }^{6}$ Service des maladies infectieuses et réanimation médicale. Centre Hospitalier Universitaire Rennes, 2 rue Henri le Guilloux, 35033 Rennes, France.

\section{Corresponding author}

Fabien Fily 
Tel: 0669085165, Tel: 0299212121, Fax : 0299212726, Email: f.fily@ch-stmalo.fr

Keywords: bone and joint infection; moxifloxacin; rifampicin

Mots clés : infection ostéoarticulaire ; moxifloxacine; rifampicine 


\section{ABSTRACT}

Objective. We aimed to describe the effectiveness and safety of the moxifloxacin-rifampicin combination in non-staphylococcal Gram-positive orthopedic implant-related infections.

Methods. Patients treated with the moxifloxacin-rifampicin combination for an implantrelated infection from November 2014 to November 2016 were retrospectively identified from the database of the referral centers for bone and joint infections in Western France.

Results. Twenty-three cases of infection due to Streptococcus spp. ( $n=12)$, Cutibacterium acnes $(n=6)$, and Enterococcus faecalis $(n=5)$ were included. Ten patients with hip prosthesis were included. Infection was polymicrobial in 11 cases. According to the MIC, moxifloxacin was 1.5 to 11.7 times as active as levofloxacin against non-staphylococcal Gram-positive bacteria. We reported an $81.8 \%$ success rate, and no severe adverse effect.

Conclusion. The moxifloxacin-rifampicin combination is a valuable alternative for the treatment of non-staphylococcal Gram-positive implant-related infections because of the good activity of moxifloxacin against these bacteria and the potential activity on the biofilm. 


\section{RESUME}

Objectif. Décrire l'efficacité et la tolérance de l'association moxifloxacine et rifampicine dans le traitement des infections ostéoarticulaires sur matériel à Gram positif hors staphylocoque. Méthodes. Les cas traités entre novembre 2014 et novembre 2016 ont été rétrospectivement identifiés dans la base de données des Centres de Référence pour les Infections Ostéoarticulaires Complexes du Grand Ouest.

Résultats. Vingt-trois cas d'infections à Streptococcus spp. $(n=12)$, Cutibacterium acnes $(n=6)$ et Enterococcus faecalis $(n=5)$ ont été inclus. L'infection était polymicrobienne dans 11 cas. Les concentrations minimales inhibitrices de la moxifloxacine étaient 1,5 à 11,7 fois inférieures à celles de la lévofloxacine. Le taux de succès était de 81,8\%. Aucun effet indésirable grave n’a été observé.

Conclusion. L'association moxifloxacine-rifampicine est une alternative intéressante pour le traitement des infections sur matériel à Gram positif hors staphylocoque, du fait d'une bonne activité de la moxifloxacine contre ces bactéries et d'une potentielle activité sur le biofilm. 


\section{INTRODUCTION}

The recommended treatment for orthopedic implant-related infections caused by nonstaphylococcal Gram-positive bacteria (NSGPB), mainly Streptococcus spp., Enterococcus spp., and Cutibacterium acnes, is intravenous penicillin $\mathrm{G}$ or amoxicillin [1,2]. However, the duration of intravenous treatment and best oral regimen remain controversial.

Rifampicin usually has a good in vitro activity against NSGPB [3-5] and, among fluoroquinolones, moxifloxacin usually has the lowest minimum inhibitory concentration (MIC) [6].

We aimed to describe the safety and effectiveness of the rifampicin-moxifloxacin oral combination in non-staphylococcal Gram-positive orthopedic implant-related infections.

\section{METHODS}

We performed a retrospective study and identified cases from the database of the six reference centers for bone and joint infections in Western France (Tours, Rennes, Angers, Brest, Nantes, Poitier), which can be solicited for advice or for clinical management. The charts of all patients who received the moxifloxacin-rifampicin combination between November 2014 and November 2016 were reviewed. Patients were included if signs of infection related to the orthopedic implant were present (fever, redness, sinus tract, or implant loosening) and if Streptococcus spp. or Enterococcus spp. were isolated from at least two joint aspirates and/or intraoperative samples. Three or more positive intraoperative samples were required for $C$. acnes. Infection was classified as polymicrobial when several bacteria were isolated from the intraoperative samples (at least two samples for coagulase-negative staphylococci). Infections were classified as follows: $i$ ) early postoperative infection, when the infection was 
diagnosed within the first 30 days following surgery, ii) late chronic infection, when the infection was diagnosed more than 30 days after surgery with gradual, indolent onset of symptoms, iii) acute hematogenous infection, when the infection was diagnosed with acute onset in a previously well-functioning prosthesis. MICs were measured using the E-test method (ETEST ${ }^{\circledR}$ bioMérieux).

The follow-up period was calculated from the start of treatment with rifampicin and moxifloxacin. Failure was defined as death related to the infection, additional surgery to control the infection, or when signs of infection remained or reappeared during follow-up. Success was assessed only for patients with a 12-month follow-up period minimum. This study obtained review and approval from Rennes University Hospital Ethics Review Board.

\section{RESULTS}

Twenty-three cases were included (Table I), all from the center of reference of Rennes (20 cases managed in Rennes hospital, and three cases managed in Saint-Malo hospital). The median age was 61 years (range, 29-92), the median weight was $76 \mathrm{~kg}$ (range, 58-114), and the sex ratio was 1.5. Underlying conditions included moderate renal and cardiac dysfunction (patients 1 and 9), alcohol abuse (patient 16), osteosarcoma (patients 18 and 22), and rheumatoid arthritis treated with anti-TNF therapy (patient 17). The most frequent orthopedic implants were hip prosthesis $(n=10,43.4 \%)$ and plates for long bone osteosynthesis $(n=5$, 21.8\%). Infections were classified as late chronic infections ( $n=12,52.1 \%$ ), early postoperative infections $(n=7,30.4 \%)$, or acute hematogenous infections $(n=4,17.4 \%)$. Streptococci were isolated in 12 cases (52.0\%), C. acnes in six cases (26.0\%), and Enterococcus faecalis in five cases $(21.7 \%)$. The infection was polymicrobial in 11 cases $(47.8 \%)$, most frequently with Staphylococcus aureus $(n=7)$. Initial surgical management was debridement and implant 
retention for all early postoperative infections (except for patient 15) and acute hematogenous infections. Implant exchange $(n=8)$ or removal $(n=4)$ was performed for all late chronic infections. Twenty patients received empirical post-operative antibiotic treatment (in patients 4,5 , and 8 , no infection was suspected prior to surgery; treatment was started when the microbiological results were available), including a beta-lactam $(n=14)$, vancomycin $(n=3)$, or vancomycin plus a beta-lactam $(n=3)$. Culture-guided intravenous treatment was amoxicillin alone for monomicrobial infections $(n=11)$, cefazolin for co-infections with streptococci and S. aureus ( $n=4)$, or beta-lactam/beta-lactamase inhibitor $(n=7)$. The median duration of total intravenous treatment was 14 days (range, $0-42$ ) before oral switch to the moxifloxacin-rifampicin combination. Median dosage of rifampicin was $11 \mathrm{mg} / \mathrm{kg} /$ day (range, 8-13), mostly once a day. Only one patient, weighing $114 \mathrm{~kg}$, received moxifloxacin $400 \mathrm{mg}$ twice a day because peak serum concentration was considered low $(1.7 \mathrm{mg} / \mathrm{l})$ with $400 \mathrm{mg}$ once a day. No other antibiotic was associated, even in cases of polymicrobial infections. MICs for both moxifloxacin and levofloxacin were available for 20 patients. Compared with levofloxacin, moxifloxacin was 2.6 to 11.7 times more active against Streptococcus spp. (range of MICs, $0.064-0.25 \mathrm{mg} / \mathrm{l}$ ), 1.5 to 8 times more active against $C$. acnes (range, 0.047$0.125 \mathrm{mg} / \mathrm{l}$ ), and 2 to 5.3 times more active against $E$. faecalis (range, $0.094-0.5 \mathrm{mg} / \mathrm{l}$ ). Total duration of antimicrobial treatment was six to 16 weeks. This regimen was followed by indefinite chronic oral antimicrobial suppression with penicillin for patients 7 and 22 .

In patient 21 only, moxifloxacin was discontinued after 15 days because of dizziness and arthromyalgia. Gastrointestinal tract disorder was the most frequent adverse effect reported $(n=3)$. Spontaneously resolving liver function abnormalities (isolated elevated hepatic enzymes, grade two) were reported in three patients. One patient (patient 9) died of hemorrhagic shock complicating treatment with heparin. After a median follow-up of 20.5 
months (range, 13-44) the global success rate was $81.8 \%(18 / 22)$. Among the four failures, only patient 4 experienced relapse. Patients 12 and 21 presented with re-infections with $S$. epidermidis and patient 23 experienced clinical failure, not microbiologically confirmed.

\section{DISCUSSION}

We reported our experience with the oral combination of moxifloxacin and rifampicin in the treatment of non-staphylococcal Gram-positive orthopedic implant-related infections, which highlights high success rate (81.8\%) despite factors usually associated with poor outcome: $i)$ polymicrobial infection in $47.8 \%$ of cases, ii) isolation of Enterococcus spp. in $18.8 \%$ of cases, iii) and implant retention in $40.9 \%$ of cases [1,7]. We only deplored one relapse, for which surgical procedure and timing of antibiotic initiation were not optimal. Recent studies on prosthetic joint infections involving NSGPB reported a "not-so-good" success rate despite prolonged intravenous therapy: $58 \%$ in a large multicenter study of Streptococcus spp. infections when implant was retained [8] and 56\% in Enterococcus spp. infections [7]. However, in a series of $C$. acnes infections treated with a rifampicin combination therapy in two-thirds of cases, success rate was close to $90 \%$ [9]. The good success rate reported in the present article might be explained by the effectiveness of the moxifloxacin-rifampicin combination on the biofilm usually associated with foreign-body infection. Indeed, rifampicin alone or in combination with a fluoroquinolone has been shown to be effective in vitro against E. faecalis and C. acnes biofilms [4,5]. Moreover, two recent observational studies advocated the use of rifampicin in streptococcal periprosthetic joint infections, particularly in cases of implant retention $[8,10]$. The favorable blood/bone ratio [11] and the high bioavailability of moxifloxacin and rifampicin also allow a short initial intravenous treatment; median duration was 14 days in our series. The combination of moxifloxacin and rifampicin has already been 
used in staphylococcal prosthetic joint infection and the success rate was not different than that reported with the levofloxacin-rifampicin combination in a recent retrospective study [12]. In our series, the seven cases of co-infection with $S$. aureus were associated with favorable outcomes.

Our data confirms the in vitro superiority of moxifloxacin against NSGPB, which was 1.5 to 11.7 as active as levofloxacin according to MICs. There were no other cases than those included in our study, with both levofloxacin and moxifloxacin MICs available, over the study period in our two centers. However, activity of moxifloxacin against Enterococcus spp. is unpredictable, particularly against E. faecium [6]; it seems preferable to determine MIC before choosing this drug. Pharmacokinetic interaction between rifampicin and moxifloxacin is expected to be weak because moxifloxacin is entirely metabolized during the phase II of glucuronidation and sulfation whereas rifampicin is particularly known as an inducer of phase I isoenzymes of cytochrome P450. However, reduction of moxifloxacin plasma concentration has been reported in patients treated with rifampicin and isoniazid for tuberculosis [13]. The clinical relevance of this interaction is still debated [12,14] and extrapolation to nontuberculosis patients has to be confirmed.

The European Medicines Agency raised concerns about the potential hepatotoxicity of moxifloxacin and recommended in 2008 a restriction of its use. However, a recent case control study was unable to show a greater risk for moxifloxacin compared with levofloxacin or amoxicillin [15]. Only mild and transient elevations in aminotransferase levels were reported in our study. Fluoroquinolones, and particularly moxifloxacin, have been associated with prolongation of the QT interval by inhibition of the cardiac potassium channel, but few studies have explored the clinical impact. In a nationwide cohort study in Taiwan the use of moxifloxacin was associated with a higher risk of ventricular arrhythmia or cardio-vascular 
death compared with amoxicillin-clavulanic acid. However, the association persisted after treatment discontinuation, suggesting that other factors than the treatment itself might be involved. Moreover, the absolute risk of cardiovascular death associated with the use of moxifloxacin was very low and not significantly higher compared with levofloxacin [16]. No cardiac event was reported in our series, but an electrocardiogram should be performed before initiating moxifloxacin to look for QT interval prolongation.

\section{Conclusion}

Our results suggest that the moxifloxacin-rifampicin combination is a valuable alternative for the treatment of non-staphylococcal Gram-positive implant-related infections because of the good activity of moxifloxacin against these bacteria and the potential activity of this combination therapy on the biofilm.

\section{Disclosure of interests}

The authors declare no conflict of interests.

\section{Acknowledgment}

FF and CA conceived and designed the study. FF, AJG, TG, MCV, and MD contributed to the acquisition of data. FF analyzed the data. FF, EP, and MCV wrote the final report. All authors reviewed and approved the final version of the article.

\section{Financial support}


Centre de Référence pour les Infections Ostéo-articulaires Complexes du Grand Ouest (CRIOGO). 


\section{REFERENCES}

1. Osmon DR, Berbari EF, Berendt AR, Daniel Lew, Zimmerli W, Steckelberg JM, et al. Diagnosis and Management of Prosthetic Joint Infection: Clinical Practice Guidelines by the Infectious Diseases Society of America. Clin Infect Dis 2013;1:e1-25.

2. Stahl JP, Guery B, Bru JP, Gauzit R, Lina B, Piroth L, et al. Clinical practice recommendations. Osteoarticular infections on materials (prosthesis, implant, osteosynthesis). Med Mal Infect 2009;39:815-63.

3. Khassebaf J, Hellmark B, Davidsson S, Unemo M, Nilsdotter-Augustinsson A, Söderquist B. Antibiotic Susceptibility of Propionibacterium Acnes Isolated from Orthopaedic Implant-Associated Infections. Anaerobe 2015;32:57-62.

4. Furustrand Tafin U, Corvec S, Betrisey B, Zimmerli W, Trampuz A. Role of Rifampin against Propionibacterium Acnes Biofilm in Vitro and in an Experimental Foreign-Body Infection Model. Antimicrob Agents Chemother 2012;56:1885-91.

5. Holmberg A, Mörgelin M, Rasmussen M. Effectiveness of Ciprofloxacin or Linezolid in Combination with Rifampicin against Enterococcus Faecalis in Biofilms. J Antimicrob Chemother 2012;67:433-39.

6. Hoogkamp-Korstanje JA, Roelofs-Willemse J. Comparative in Vitro Activity of Moxifloxacin against Gram-Positive Clinical Isolates. J Antimicrob Chemother 2000;45:31-39.

7. Tornero E, Senneville E, Euba G, Petersdorf S, Rodriguez-Pardo D, Lakatos B, et al. Characteristics of Prosthetic Joint Infections Due to Enterococcus Sp. and Predictors of Failure: A Multi-National Study. Clin Microbiol Infect 2014;20:1219-24.

8. Lora-Tamayo J, Senneville E, Ribera A, Bernard L, Dupon M, Zeller V, at al. The Not-So-Good Prognosis of Streptococcal Periprosthetic Joint Infection Managed by Implant Retention: The Results of a Large Multicenter Study. Clin Infect Dis 2017;64:1742-52. 
9. Jacobs AM, Van Hooff ML, Meis JF, Vos F, Goosen JH. Treatment of prosthetic joint infections due to Propionibacterium. Similar results in 60 patients treated with and without rifampicin. Acta Orthop 2016;87:60-6.

10. Fiaux E, Titecat M, Robineau O, Lora-Tamayo J, El Samad Y, Etienne M, et al. Outcome of patients with streptococcal prosthetic joint infections with special reference to rifampicin combinations. BMC infectious diseases 2016;16:568.

11. Landersdorfer CB, Kinzig M, Hennig FF, et al. Penetration of Moxifloxacin into Bone Evaluated by Monte Carlo Simulation. Antimicrob Agents Chemother 2009; 53:2074-81.

12. Wouthuyzen-Bakker M, Tornero E, Morata L, Nannan Panday PV, Jutte PC, Bori G, et al. Moxifloxacin plus Rifampin as an Alternative for Levofloxacin plus Rifampin in the Treatment of a Prosthetic Joint Infection with Staphylococcus Aureus. Int J Antimicrob Agents 2018;51:38-42.

13. Nijland HM, Ruslami R, Suroto AJ, Burger DM, Alisjahbana B, van Crevel R, et al. Rifampicin Reduces Plasma Concentrations of Moxifloxacin in Patients with Tuberculosis. Clin Infect Dis 2007;8:1001-7.

14. Manika K, Chatzika K, Papaioannou M, et al. Rifampicin-Moxifloxacin Interaction in Tuberculosis Treatment: A Real-Life Study. Int J Tuberc Lung Dis 2015; 19:1383-87.

15. Kaye JA, Castellsague J, Bui CL, et al. Risk of Acute Liver Injury Associated with the Use of Moxifloxacin and Other Oral Antimicrobials: A Retrospective, Population-Based Cohort Study. Pharmacotherapy 2014; 34:336-49.

16. Chou HW, Wang JL, Chang CH, Lai CL, Lai MSL, Chan KA. Risks of Cardiac Arrhythmia and Mortality among Patients Using New-Generation Macrolides, Fluoroquinolones, and $\beta$-Lactam/ $\beta$ Lactamase Inhibitors: A Taiwanese Nationwide Study. Clin Infect Dis 2015; 60:566-77. 
Tableau I. Infections ostéoarticulaires sur matériel à Gram positif hors staphylocoque traitées par l'association moxifloxacine et rifampicine

Table I. Non-staphylococcal Gram-positive implant-related infections treated with the moxifloxacin-rifampicin combination (23 patients)

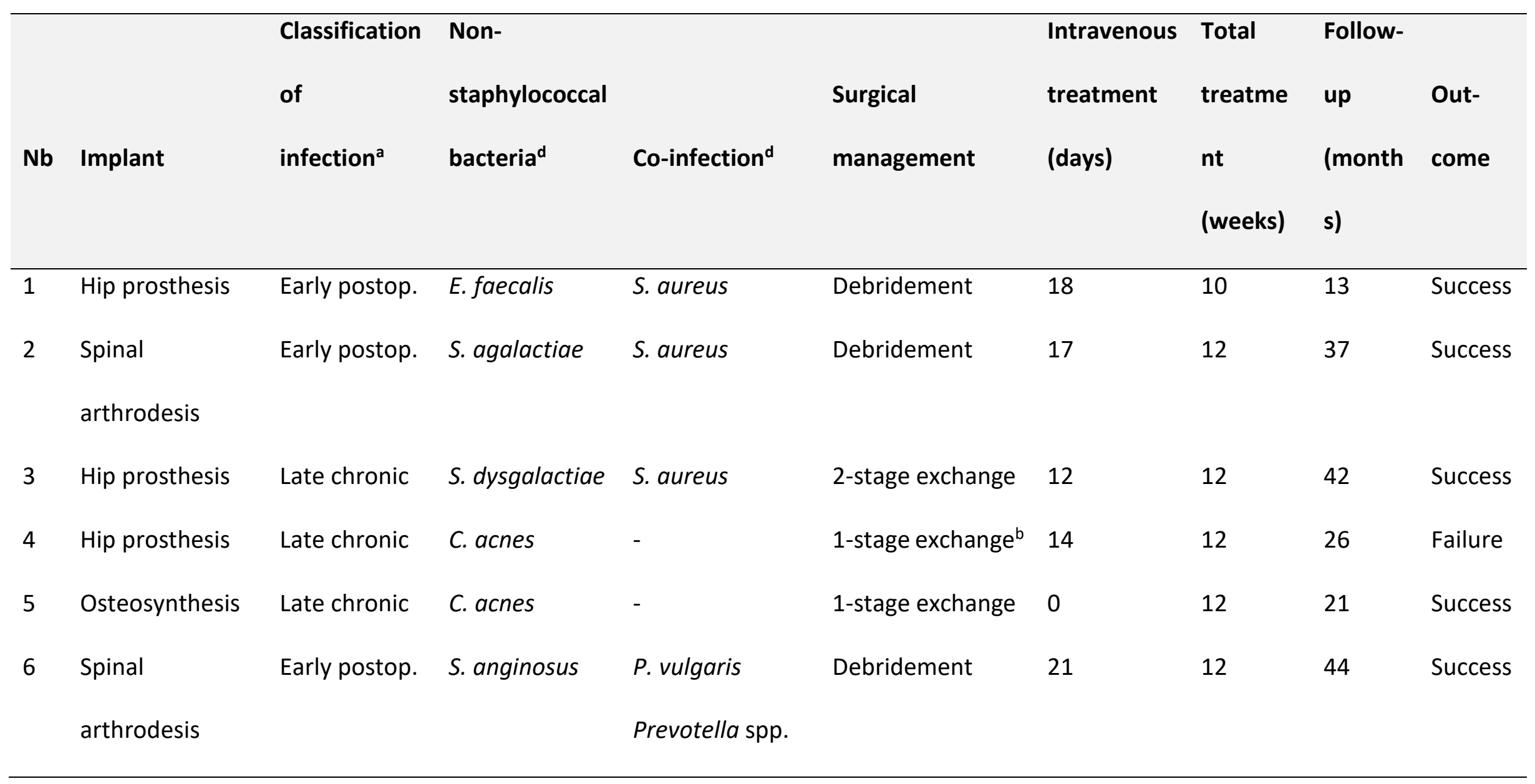




\begin{tabular}{|c|c|c|c|c|c|c|c|c|c|}
\hline 7 & Knee prosthesis & Acute & S. pyogenes & - & Debridement & 21 & 12 & 20 & Success \\
\hline 8 & Hip prosthesis & Late chronic & C. acnes & - & 1-stage exchange & 42 & 12 & 27 & Success \\
\hline \multirow[t]{2}{*}{9} & Hip prosthesis & Early postop. & E. faecalis & S. aureus & Debridement & 19 & 1.2 & 0.5 & Death \\
\hline & & & & P. vulgaris & & & & & \\
\hline 10 & Hip prosthesis & Late chronic & S. pneumoniae & - & 2-stage exchange & 14 & 10 & 21 & Success \\
\hline 11 & Hip prosthesis & Acute & S. gordonii & - & Debridement & 14 & 12 & 23.5 & Success \\
\hline 12 & Osteosynthesis & Late chronic & C. acnes & - & Removal & 18 & 12 & 3.5 & Failure \\
\hline \multirow[t]{2}{*}{13} & Ankle & Late chronic & E. faecalis & E. cloacae & Removal & 12 & 6 & 20 & Success \\
\hline & arthrodesis & & & A. prevotii & & & & & \\
\hline \multirow[t]{2}{*}{14} & Spinal & Late chronic & C. acnes & - & Removal & 19 & 12 & 24 & Success \\
\hline & arthrodesis & & & & & & & & \\
\hline \multirow[t]{2}{*}{15} & Osteosynthesis & Early postop. & E. faecalis & S. aureus & Removal & 12 & 8 & 21 & Success \\
\hline & & & & E. cloacae & & & & & \\
\hline 16 & Osteosynthesis & Early postop. & S. constellatus & Prevotella spp. & Debridement & 21 & 6 & 20 & Success \\
\hline 17 & Hip prosthesis & Late chronic & S. dysgalactiae & S. aureus & 2-stage exchange & 9 & 6 & 15 & Success \\
\hline
\end{tabular}




\begin{tabular}{|c|c|c|c|c|c|c|c|c|c|}
\hline 18 & Hip prosthesis & Early postop. & C. acnes & - & Debridement & 21 & 15 & 20 & Success \\
\hline 19 & Hip prosthesis & Late chronic & S. agalactiae & - & 1-stage exchange & 9 & 12 & 20 & Success \\
\hline 20 & Osteosynthesis & Late chronic & S. dysgalactiae & S. aureus & Removal & 9 & 6 & 17 & Success \\
\hline 21 & $\mathrm{PIP}^{\mathrm{C}}$ prosthesis & Late chronic & E. faecalis & S. schleiferi & 2-stage exchange & 7 & 8 & 2.5 & Failure \\
\hline 22 & Knee prosthesis & Acute & S. dysgalactiae & - & Debridement & 38 & 16 & 15.5 & Success \\
\hline 23 & Knee prosthesis & Acute & S. dysgalactiae & - & Debridement & 11 & 1 & 0.75 & Failure \\
\hline \multicolumn{10}{|c|}{ a Early postoperative ("early postop."), late chronic or acute hematogenous ("acute") ${ }^{\text {b} P a r t i a l ~ e x c h a n g e ~(f e m o r a l ~ i m p l a n t ~ o n l y) ~ f o r ~ p a t i e n t s ~} 4$} \\
\hline \multicolumn{10}{|c|}{ dEnterococcus faecalis, Streptococcus agalactiae, Streptococcus dysgalactiae, Streptococcus anginosus, Streptococcus pyogenes, Streptococcus } \\
\hline cor & tellatus, Streptoc & ccus gordonii, & Streptococcus $p$ & pneumoniae, & Cutibacterium acnes, & Enterococcus & faecalis, & Staphylococcus & aureus, \\
\hline
\end{tabular}

